\title{
Elevated Interleukin-1 Expression In Human Neonatal Neutrophils
}

\author{
JOSEPHINE CONTRINO, PETER J. KRAUSE, NADIA SLOVER, AND DONALD KREUTZER \\ Department of Pathology /J.C., D.K.J. University of Connecticut Health Center, and the Departme'nt of Pediatrics \\ (P.J.K., N.S.J, IIartford Hospital, The University of Connecticut School of Medicine. \\ Farmington, Conmecticut, 06030-3105
}

\begin{abstract}
Newborn infants have an increased morbidity and mortality from infection caused in part by diminished polymorphonuclear leukocyte (PMIN) function and impaired recruitment of PNIN to sites of inflammation. Recent studies in our laboratory and others have demonstrated the in vitro expression of several cytokines, including IL-1- $\beta$, in adult human peripheral blood PMIN. Because newborn infants have an impaired inflammatory response, we sought to compare the synthetic capability and regulation of cytokine expression in neonatal and adult PNIN. In our present studies, we found that tumor necrosis factor- $\alpha$ and lipopolysaccharide could induce IL-1- $\beta$ expression in both neonatal and adult PMN and that neonatal PMIN produced significantly more IL-1- $\beta$ when compared with adult PMIN. The PMIN chemotactic peptide fMlet-Leu-Phe did not induce IL-1- $\beta$ expression in either adult or neonatal PMIN. Elevated cytokine expression by neonatal PMN may play an important role in the regulation of the immune and inflammatory systems at sites of injury and infection in neonates. (Pediatr Res 34: 249-252, 1993)
\end{abstract}

\section{Abbreviations}

PMIN, polymorphonuclear leukocyte

LPS, lipopolysaccharide

TNF, tumor necrosis factor

TNF- $\alpha$, tumor necrosis factor- $\alpha$

GM-CSF, granulocyte monocyte colony stimulating factor NILP, N-formyl-methionyl-leucyl-phenylalanine

Proinflammatory cytokines such as IL-1- $\beta$, TNF, IL-6, and IL- 8 have been demonstrated in cells and tissue in several inflammatory diseases. The local expression of these cytokines is thought to be critical in the recruitment and activation of inflammatory cells. For example, IL-1- $\beta$ and TNF have been shown to induce the recruitment of PMN in vivo $(1,2)$. In vitro pretreatment of PMN with IL-1- $\beta$, TNF, or GM-CSF has been shown to prime oxidative metabolism and phagocytosis in these cells (3-6). IL-1- $\beta$ and TNF also appear to stimulate release of other mediators of inflammation including thromboxane, 6-ketoprostaglandin $F_{1 a}$, and prostaglandin $E_{2}(7)$.

Previously, a wide variety of cell types such as monocytes, endothelial cells, and fibroblasts have been shown to produce IL- $1-\beta$ in response to various factors, such as endotoxins and cytokines. Historically, PMN were not considered a potential source of cytokines because they were thought to be terminally differentiated without protein synthetic capability. Interestingly,

Received August 7, 1992; accepted January 22, 1993.

Correspondence: Dr. Donald Kreutzer, Department of Pathology, University of Connecticut School of Medicine, Farmington, CT, 06030-3105. recent studies in our laboratory and others have shown that PMN are able to synthesize proteins when given the appropriate stimulus $(6-11)$. For (xample, we have demonstrated that adult human peripheral blood PMN can produce IL-1- $\beta$ in response to IL-1-a, IL-1- $\beta$, and TNF- $\alpha(10,11)$. Our studies also demonstrated that IL-1 $\beta$ or TNF induced PMN to transiently express IL-1- $\beta$ mRNA, with peak expression at $1 \mathrm{~h}$, and return to untreated levels by $2 \mathrm{~h}$. In other studies, adult PMN have been shown to produce IL- $1-\beta$ in response to TNF, LPS, or GM-CSF $(12,13)$. To our knowledge, nothing is known about the ability of neonatal PMN to produce cytokines.

Impaired neonatal host defense is thought to be at least partially responsible for increased neonatal morbidity and mortality from infection (14-16). Inasmuch as IL-1- $\beta$, TNF, LPS, and GM-CSF have been shown to be important priming or activating agents of PMN, we investigated their effect on IL-1- $\beta$, TNF, and GM-CSF. expression in neonatal and adult PMN. Anticipating decreased PMN cytokine expression by neonatal PMN, we were surprised to find that TNF- $\alpha$ and LPS could induce IL-1- $\beta$ expression in both neonatal and adult PMN and that neonatal PMN consistently produced more amounts of IL- $1-\beta$ than adult PMN. The recognition of cytokines as important regulators of immune and inflammatory reactions suggests that elevated IL$1-\beta$ expression by neonatal PMN may be significant for immune and inflammatory regulation in the neonate.

\section{MATERIALS AND METHODS}

Adult and neonatal P.MN. Placentas were obtained from healthy women who underwent repeat cesarean sections under regional anesthesia, with no complications of pregnancy, labor, or delivery and whose newborns were in good health. Blood was obtained from the fetal side of placentas (neonatal cord blood) within $5 \mathrm{~min}$ of birth. Blood was also obtained from healthy adult volunteers. All blood samples were immediately mixed with preservative-free sodium heparin $(50 \mu \mathrm{L} / \mathrm{mL}$ blood) and brought to the laboratory for analysis. Informed consent to sample blood was obtained from all parents or adult subjects in accordance with the University of Connecticut and Hartford Hospital Institutional Review guidelines.

PMN purification. Human and neonatal PMN were isolated from blood using Ficoll-Hypaque density centrifugation followed by $3 \%$ dextran (Pharmachem, Bethlehem, PA) sedimentation (17). Residual red blood cells were hypotonically lysed, and the PMN were washed three times with $50 \mathrm{~mL}$ of $0.05 \mathrm{M}$ PBS, pH 7.4. The resulting cells were 95 to $98 \% \mathrm{PMN}$ as determined by morphology of Wright's stained cells and more than $99 \%$ viable as determined by trypan blue exclusion. For these studies, all cells were prepared and maintained using sterile reagents and techniques. All reagents used for these studies were either pharmaceutical grade or contained $<0.1$ endotoxin units $/ \mathrm{mL}$ of endotoxin as determined by the amebocyte lysate assay (Whittaker, Walkersville, MD). 


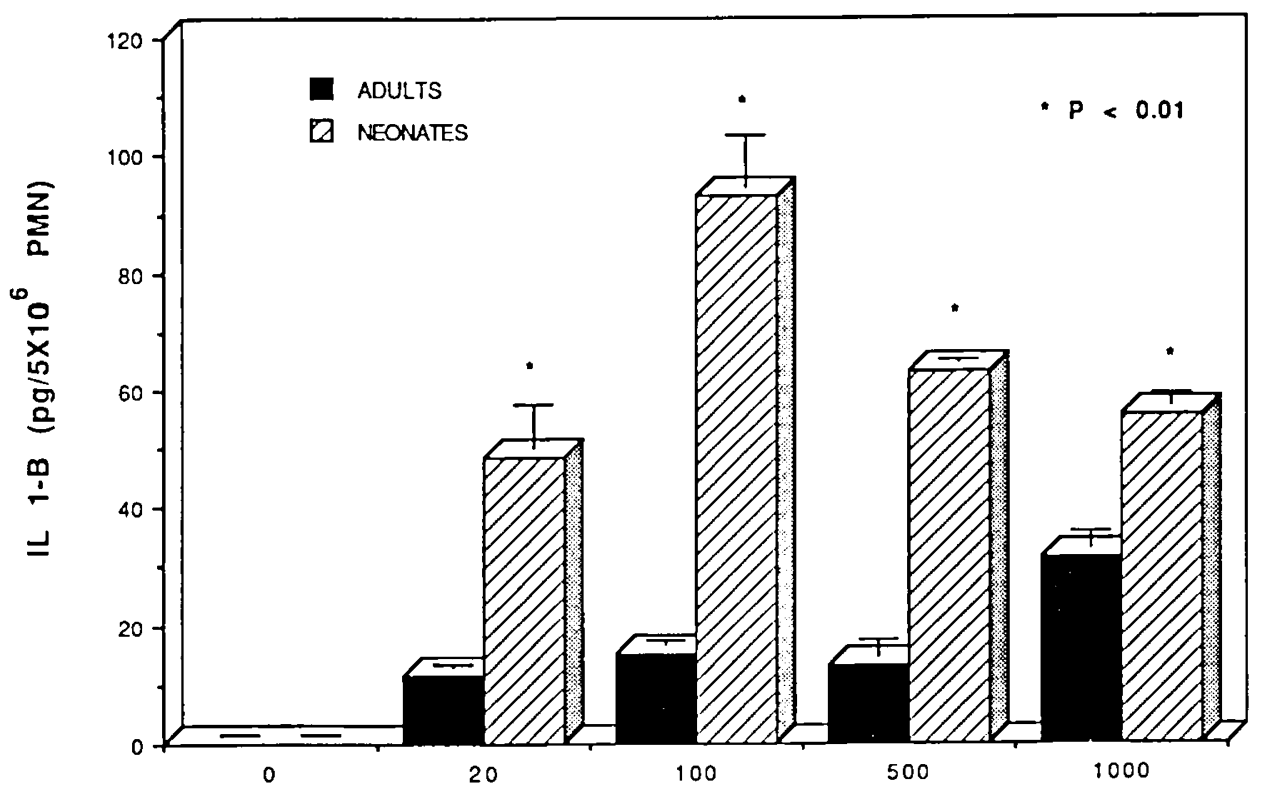

TNF UNITS/ML

Fig. 1. Dose-dependent IL-1- $\beta$ response to TNF stimulation in neonatal and adult PMN. PMN obtained from neonates and adults were simultaneously incubated for $3 \mathrm{~h}$ at $37^{\circ} \mathrm{C}$ with varying doses of TNF, and the amount of IL-1- $\beta$ antigen determined in PMN lysates (i.e. cell associated) and supernatants. Mean values \pm 1 SEM are shown for 11 experiments (adults, solid hars; neonates, striped bars). There was significantly more IL- $1-\beta$ antigen detected in neonatal PMN lysates at all TNF concentrations $(p<0.01)$ than in adult PMN lysates. No detectable IL-1- $\beta$ antigen was seen in the PMN supernatants of neonatal or adult PMN with any TNF concentrations tested; thus, supernatant data are not shown.

$P M N$ culture conditions. For all studies, PMN were cultured at $37^{\circ} \mathrm{C}$ with $5 \% \mathrm{CO}_{2}$ in minimum essential medium (GIBCO, Grand Island, NY) containing 10\% FCS (HyClone Inc., UT). To initiate our studies, we evaluated the ability of TNF $(500 \mathrm{U} / \mathrm{mL}$; $\left.1.5 \times 10^{-9} \mathrm{M}\right)$ to induce IL-1 $-\beta$ expression in both neonatal and adult PMN. Briefly, purified adult and neonatal PMN $\left(1 \times 10^{7} /\right.$ $\mathrm{mL}$ ) were incubated in polypropylene microcentrifuge tubes in minimal essential medium containing $10 \%$ low endotoxin fetal serum with and without TNF $\left(500 \mathrm{U} / \mathrm{mL} ; 1.5 \times 10^{-9} \mathrm{M}\right)$. After incubation for various periods $(1,2,3$, and $4 \mathrm{~h})$ at $37^{\circ} \mathrm{C}$ in a humidified $5 \% \mathrm{CO}_{2}$ atmosphere, PMN and supernatants were harvested by centrifugation at $500 \times g$ for $10 \mathrm{~min}$ at $4^{\circ} \mathrm{C}$. The resulting pellet was lysed by the addition of $200 \mu \mathrm{L}$ of lysing solution $(0.1 \%$ Triton X-100 plus $10 \%$ fetal serum in minimum essential medium). The cell lysates and supernatants were evaluated for IL-1- $\beta$ antigen by a commercially available ELISA (Cistron Biotechnology, Pine Brook, NJ).

Once we established the optimum incubation period for cytokine expression $(3 \mathrm{~h})$, we evaluated the ability of various concentrations of TNF $(0,20,100$, and $500 \mathrm{U} / \mathrm{mL})$ to induce IL-1- $\beta$ expression in both neonatal and adult PMN at $3 \mathrm{~h}$. For these studies, purified PMN were treated using the same experimental conditions as described above but were stimulated with various concentrations of TNF $(0,20,100$, and $500 \mathrm{U} / \mathrm{mL} ; 0 \mathrm{M}, 6 \times$ $10^{-11} \mathrm{M}, 3 \times 10^{-10} \mathrm{M}, 1.5 \times 10^{-9} \mathrm{M}$ ) for $3 \mathrm{~h}$. The PMN lysates and resulting supernatants were again harvested by centrifugation at $500 \times g$ for $10 \mathrm{~min}$ at $4^{\circ} \mathrm{C}$. The resulting pellet was lysed with $0.1 \%$ triton (see above) and, with the corresponding supernatant, was evaluated for IL- $1-\beta$ antigen by ELISA.

We also investigated whether other stimuli (IL-1- $\beta$, LPS, and IMLP) could induce IL- $1-\beta$, TNF, and GM-CSF expression in either neonatal or adult PMN. Purified PMN $\left(1 \times 10^{7} / \mathrm{mL}\right)$ were treated under the same experimental conditions as described above but were stimulated with or without IL- $1-\beta(1 \mathrm{ng} / \mathrm{mL} ; 5.9$ $\left.\times 10^{-11} \mathrm{M}\right)$, LPS $(10 \mu \mathrm{g} / \mathrm{mL})$, and $\mathrm{fMLP}\left(1 \times 10^{-7} \mathrm{M}\right)$ for 3 and $24 \mathrm{~h}$. After each incubation period, the PMN and supernatants were harvested as described above. The resulting neonatal and adult cell lysates and their corresponding supernatants were analyzed for IL-1- $\beta$, TNF, and GM-CSF antigen by commercially available ELISAs (Cistron Biotechnology, Pine Brook, NJ).

Statistical analysis. All data for these studies are expressed as mean \pm SEM and analyzed using paired $t$ test. Statistics were performed with Statview 512+ program (Brainpower, Calabasas, CA) on a Macintosh II computer (Apple Computer, Cupertino, CA). A $p$ value of $<0.05$ was considered significant.

\section{RESULTS}

TNF induction of cytokine expression. Based on our previous studies of IL-1- $\beta$ antigen expression in adult PMN, we initiated experiments on the effect of TNF $\left(500 \mathrm{U} / \mathrm{mL} ; 1.5 \times 10^{-9} \mathrm{M}\right)$ on IL- $1-\beta$ antigen expression in neonatal and adult PMN. Because our previous studies indicated that TNF induced IL- $1-\beta$ expression, which generally peaked in less than $4 \mathrm{~h}$ poststimulation, we evaluated IL- $1-\beta$ expression in adult and neonatal PMN at 1 to $4 \mathrm{~h}$ poststimulation. Our initial studies indicated that TNF induced significant cell associated IL- $1-\beta$ antigen expression in both neonatal and adult PMN compared with corresponding control (nonstimulated) PMN. Peak expression was seen at $3 \mathrm{~h}$ post-TNF exposure (i.e. $57 \pm 6 \mathrm{pg} / 10^{6}$ adult PMN versus $76 \pm$ $6 \mathrm{pg} / 10^{6}$ neonatal $\left.\mathrm{PMN}\right)$. Throughout the $1-$ to 4 -h incubation time, control (nonstimulated) PMN produced only negligible amounts of IL- $1-\beta\left(0.2 \pm 0.1\right.$ to $0.3 \pm 0.2 \mathrm{pg} / 10^{6}$ adult PMN versus $0.01 \pm 0.001$ to $2 \pm 0.8 \mathrm{pg} / 10^{6}$ neonatal $\mathrm{PMN}$ ). In addition, neither adult or neonatal culture supernatants of these cells had detectable IL- $1-\beta$ antigen after any incubation time (1 to $4 \mathrm{~h}$ ), with or without TNF stimulation.

We next determined the influence of various TNF concentrations on IL-1- $\beta$ expression by neonatal and adult PMN at the single 3 -h time point. As shown in Figure 1, TNF induced a dose-dependent increase in cell associated IL-1- $\beta$ antigen expression in both neonatal and adult PMN. These studies also demonstrated that neonatal PMN produced significantly higher levels of IL-1- $\beta$ compared with TNF-stimulated adult PMN. Again, no detectable IL-1- $\beta$ antigen was seen in the PMN supernatants of neonatal or adult PMN at $3 \mathrm{~h}$ incubation with any TNF concentrations tested. These studies clearly demonstrate that neonatal 

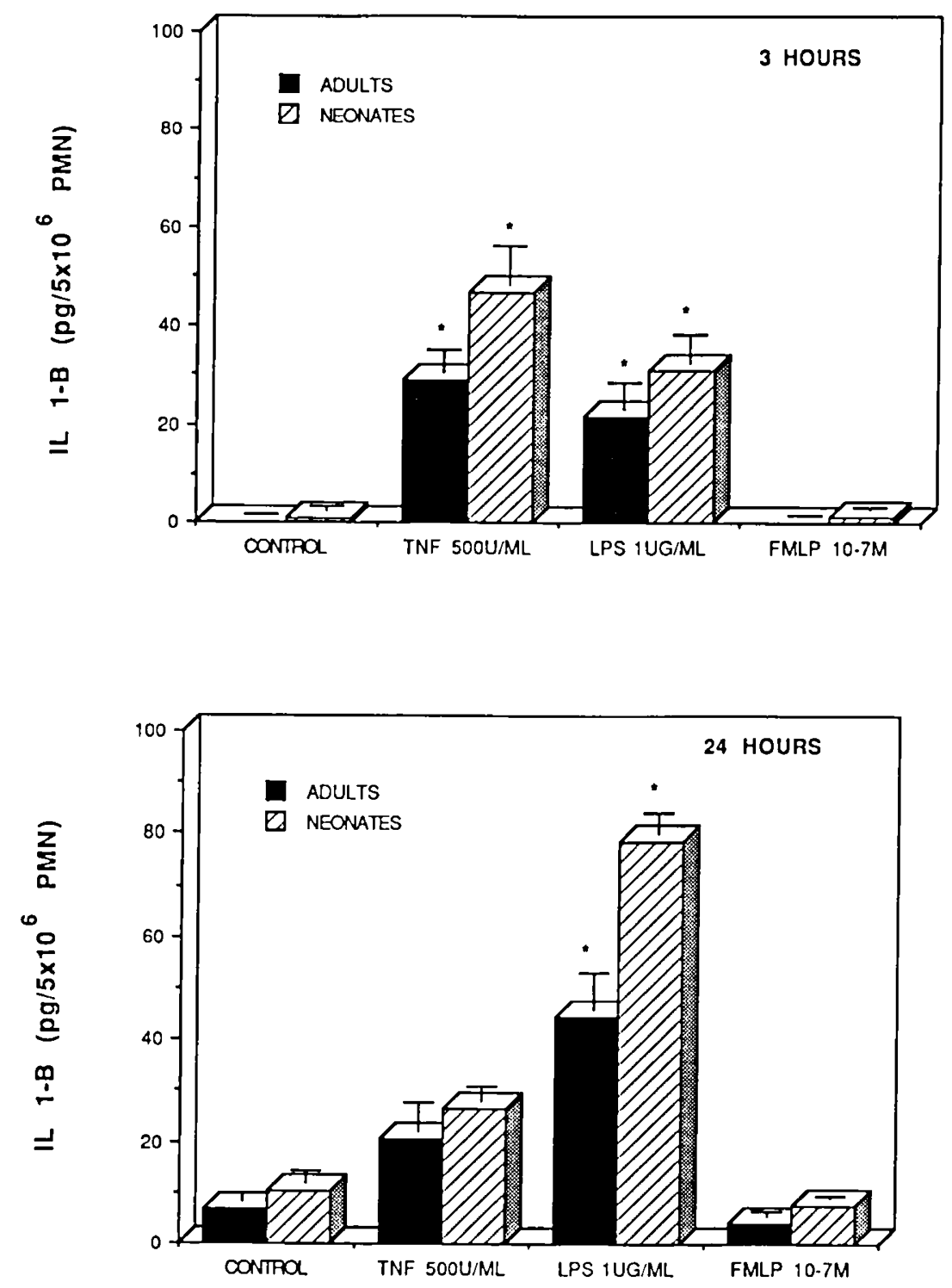

Fig. 2. PMN IL-1- $\beta$ expression in neonates and adults in response to TNF, LPS, and PMLP. PMN from neonates (striped bars) and adults (solid bars) were incubated in TNF, LPS, and IMLP for $3 \mathrm{~h}(t o p)$ and $24 \mathrm{~h}($ bottom). The amount of IL-1- $\beta$ antigen present in cell lysates after TNF stimulation at 3 and $24 \mathrm{~h}$ was significantly different from control in both neonates $(p<0.001$ and $p<0.02$, respectively) and adults $(p<0.001$ and $p<0.07$, respectively). The amount of IL-1 $-\beta$ produced after LPS stimulation at 3 and $24 \mathrm{~h}$ was also significantly different from control in both neonates $(p<0.002$ and $p<0.0001$, respectively) and adults $(p<0.005$ and $p<0.01$, respectively). There were no significant differences between control and $\mathrm{MLP}$ values for either neonates or adults.

PMN can be stimulated by a cytokine (in this case, TNF) to express IL-1 $\beta$ antigen and that neonatal PMN produce statistically more levels of the IL-1- $\beta$ cell-associated antigen when stimulated with TNF.

$T N F, L P S$, and $M M L P$ induction of cytokine expression. Additional studies were undertaken to determine whether other cell activators such as LPS or FMLP could induce IL-1- $\beta$ expression in neonatal or adult PMN. Short $(3 \mathrm{~h})$ and long $(24 \mathrm{~h})$ stimulation times using TNF, LPS, and MLP were evaluated (Fig. 2). TNF and LPS stimulated IL-1- $\beta$ expression in both neonatal and adult PMN after 3- and 24-h incubation times. Neonatal levels of IL$1-\beta$ antigen were significantly higher than those of adults. Interestingly, fMLP, a potent stimulator of PMN activation, had no effect on IL- $1-\beta$ expression of cell-associated IL- $1-\beta$ antigen after 3 or $24 \mathrm{~h}$ incubation. IL-1- $\beta$ was undetectable in supernatants after a 3-h incubation but was present in the 24-h PMN supernatants (TNF: adult $7 \pm 2 \mathrm{pg} / \mathrm{mL}$, neonate $9 \pm 3 \mathrm{pg} / \mathrm{mL}$; LPS: adult $21 \pm 9 \mathrm{pg} / \mathrm{mL}$, neonate $13 \pm 4 \mathrm{pg} / \mathrm{mL}$ ). LPS most effectively induced IL-1- $\beta$ antigen expression in both neonatal and adult PMN of all the stimuli tested. Last, we analyzed the same
PMN lysates and supernatants stimulated with TNF, LPS, IMLP, or IL-1 - $\beta$ for GM-CSF and TNF antigen expression. No detectable levels of either cytokine were found after 3- or 24-h incubations (data not shown).

\section{DISCUSSION}

Cytokines, such as IL- $1-\beta$ and TNF, have been demonstrated in the tissues of patients with a number of inflammatory diseases, and their local expression is generally thought to be critical in the regulation of tissue cells and the recruitment of cells to sites of tissue injury (18). Monocytes/macrophages have been noted to be primary sources of cytokine expression, consistent with their role as important immunoregulatory cells. In contrast, PMN have traditionally been considered effector cells with little immunoregulatory function. The discovery that PMN had the capacity to produce cytokines has altered this concept (10-13). The results of our present study clearly demonstrate that neonatal PMN can express at least one major cytokine (IL-1- $\beta$ ) when 
stimulated by TNF or LPS and that neonatal PMN IL- $1-\beta$ expression is consistently more than that of adult PMN.

Recent studies have indicated that cytokine expression is more rapid in PMN compared with monocytes and macrophages, although on a per cell basis, PMN produce relatively smaller amounts. Because PMN are generally the first inflammatory cells to arrive at sites of inflammation, PMN secretion of such cytokines as IL-1- $\beta$ could play a critical role in attracting other PMN to inflammatory sites. The rapid expression of IL-1- $\beta$ by PMN may be especially important in the augmentation of the early inflammatory response because PMN IL- $1-\beta$ expression occurs before mononuclear cells are prominent in inflammatory exudates. PMN have been shown to be recruited to sites of tissue injury by IL-1- $\beta$ and TNF in several in vivo models $(1,2)$. It has been suggested that the accumulation of PMN at inflammatory sites stimulate additional migration of PMN, but the mechanism by which this may occur has not yet been elucidated. One possible mechanism is the expression of cytokines by recruited PMN. In addition, PMN expression of such cytokines as colony stimulating factors could help stimulate the release of additional PMN from the bone marrow and might also enhance PMN function at the inflammatory site $(6,12,19)$.

In the present study, we investigated PMN cytokine expression in newborn infants where recruitment of additional PMN to inflammatory sites and enhancement of PMN function would be especially important. Newborn infants have deficiencies in a variety of host defense mechanisms that include both the regulatory and effector limbs of the immune system (14-16). Examples of the former include decreased expression of cytokines by monocytes and macrophages; examples of the latter are diminished bone marrow reserves and impaired PMN adherence, chemotaxis, and phagocytosis. Immature or deficient responses of both immune regulation and effector mechanisms are thought to contribute to the markedly increased morbidity and mortality of neonates to various infectious pathogens (14-16). Recent studies of cytokine expression in neonates have focused on monocyte and macrophages. Wilson and colleagues $(20,21)$ have shown that interferon- $\gamma, \mathrm{TNF}$, and lymphotoxin expression in human neonatal peripheral blood and cord monocytes was significantly diminished compared with that of adult monocytes. Cairo et al. (22) have found decreased GM-CSF expression in neonatal monocytes compared with those of adults. We therefore anticipated finding decreased neonatal PMN cytokine expression and were surprised to find that neonatal PMN consistently produced more amounts of IL- $1-\beta$ than adult PMN in response to LPS and TNF stimulation. The combination of increased cytokine expression by neonatal PMN and decreased cytokine expression by neonatal macrophages may contribute to regulatory dysfunction in neonatal immune and inflammatory reactions. Alternatively, the increased IL- $1-\beta$ expression by neonatal PMN may compensate for the decreased IL-1- $\beta$ expression noted in neonatal monocytes/macrophages. Thus, PMN-derived cytokines may play a key regulatory role in neonatal inflammatory and immunologic reactions.

The mechanism for increased neonatal PMN of IL-1- $\beta$ expression is unclear. The increased IL-1- $\beta$ expression may be due to increased production, decreased degradation, or both. Previous studies in our laboratory have suggested that although PMN may appear to be a morphologically homogeneous population of cells, there exists a subpopulation of viable, less mature cells (23). Neonates have a higher percentage of this relatively immature PMN subpopulation than adults $(24,25)$. It would not be surprising if these less mature cells had a greater protein synthetic capability than the more mature PMN subpopulation, thus providing an explanation for the increased IL- $1-\beta$ expression in neonatal PMN. Further studies will be necessary to determine the cause of increased neonatal PMN IL-1- $\beta$ expression and whether the increased expression is dysfunctional or an appropriate heightened response to the blunted immune response of the neonate.

\section{REFERENCES}

1. Mason MJ, Van Epps DE 1989 In vivo migration in response to interleukin-1 and tumor necrosis factor. J Leukoc Biol 45:62-68

2. Wankowicz Z, Megyeri P, Issekutz A 1988 Synergy between tumor necrosis factor and interleukin- 1 in the induction of polymorphonuclear leukocyte migration during inflammation. J Leukoc Biol 43:349-356

3. Ferrante A, Nandoskar M, Walz A, Goh D, Kowanko IC 1988 Effects of tumor necrosis factor alpha and interleukin-1 alpha and beta on human neutrophil migration, respiratory burst and degranulation. Int Arch Allergy Appl Immunol 86:82-91

4. Ozaki Y, Ohashi T, Kume S 1987 Potentiation of neutrophil function by recombinant DNA-produced interleukin-1 alpha. J Leukoc Biol 42:621-627

5. Ozaki Y, Ohashi T, Niw Y, Kume S 1988 Effect of recombinant DNAproduced tumor necrosis factor on various parameters of neutrophil function. Inflammation 12:297-309

6. Cairo MS, van de Ven C, Toy C, Mauss D, Sender L 1989 Recombinant human granulocyte-macrophage colony-stimulating factor primes neonatal granulocytes for enhanced oxidative metabolism and chemotaxis. Pediatr Res 26:395-399

7. Conti P, Reale M, Fiore S, Cancelli A, Angeletti PU, Dinarello CA 1988 Recombinant interleukin-1 and tumor necrosis factor acting in synergy to release thromboxane, 6-keto-PGF 1 alpha and $\mathrm{PGE}_{2}$ by human neutrophils. Scand J Rheumatol [Suppl] 75:318-324

8. Granelli-Piperno A, Vassall JD, Reich E 1979 RNA and protein synthesis in human peripheral blood polymorphonuclear leukocytes. J Exp Med 149:284-289

9. Hughes V, Humphreys JM, Edwards SW 1987 Protein synthesis is activated in primed neutrophils: a possible role in inflammation. Biosci Rep 7:881890

10. Marucha PT, Zeff RA, Kreutzer DL 1990 Cytokine regulation of IL 1- $\beta$ gene expression in the human polymorphonuclear leukocyte. J Immunol 145:2932-2937

11. Marucha PT, Zeff RA, Kreutzer DL 1991 Cytokine-induced IL 1- $\beta$ gene expression in the human polymorphonuclear leukocyte: transcriptional and posttranscriptional regulation by tumor necrosis factor and IL 1. J Immunol 147:2603-2608

12. Lindemann A, Riedel D, Oster W, Meue SC, Blohm D, Mertelsmann RH, Herrmann F 1988 Granulocyte/macrophage colony stimulating factor induces interleukin-1 expression by human polymorphonuclear neutrophils. J Immunol 140:837-839

13. Goh KS, Furusawa S, Kawa Y, Negishi-Okitsu S, Mizoguchi M 1989 Production of interleukin-1-alpha and beta by human peripheral polymorphonuclear neutrophils. Int Arch Allergy Appl Immunol 88:297-303

14. Krause PJ, Herson VC, Eisenfeld L. Johnson GM 1989 Enhancement of neutrophil function for treatment of neonatal infections. Pediatr Infect Dis J 8:382-389

15. Wilson CB 1990 Developmental immunology and the role of host defenses in neonatal susceptibility. In: Remington JS, Klein JO (eds) Infectious Diseases of the Fetus and Newborn Infant. WB Saunders Co, Philadelphia, pp 17-67

16. Cairo MS 1989 Neonatal neutrophil host defense. Am J Dis Child 143:40-46

17. Boyum A 1986. Isolation of lymphocytes, granulocytes, and macrophages from human blood. Scand J Clin Lab Invest [Suppl]21:77-89

18. Dinarello CA, Mier JW 1987 Lymphokines. N Engl J Med 317:940-945

19. Frenck RW, Buescher ES, Vadhan-Raj S 1989 The effects of recombinant human granulocyte-macrophage colony stimulating factor on in vitro cord blood granulocyte function. Pediatr Res 26:43-38

20. Wilson CB, Westall J, Johnston L, Lewis DB, Dower SK, Alpert AR 1986 Decreased expression of interferon-gamma by human neonatal cells. Intrinsic and regulatory deficiencies. $J$ Clin Invest 77:860-867

21. English BK, Burchett SK, English JD, Amman A, Wara DW, Wilson CB 1988 Production of lymphotoxin and tumor necrosis factor by human neonatal mononuclear cells. Pediatr Res 24:717-722

22. Cairo MS, Suen Y, Knoppel E, van de Ven C, Nguyen A, Sender L 1991 Decreased stimulated GM-CSF expression and GM-CSF gene expression but normal numbers of GM-CSF receptors in human term newborns compared with adults. Pediatr Res 30:362-367

23. Krause PJ, Todd MB, Hancock WW, Pastuszak WT, Maderazo EG, Hild DH, Kosciol CM 1990 The role of cellular maturation in neutrophil heterogeneity. Blood 76:1639-1646

24. Krause PJ, Malech HL, Kristie J, Kosciol CM, Herson VC, Eisenfeld L, Pastuszak WT, Kraus A, Seligmann B 1986 Polymorphonuclear leukocyte heterogeneity in neonates and adults. Blood 68:200-207

25. Krause PJ, Kreutzer DL, Eisenfeld, L, Herson VC, Weisman S, Bannon P, Greca N 1989 Characterization of nonmotile neutrophil subpopulations in neonates and adults. Pediatr Res 25:519-524 